\title{
ANALYSIS OF THERMOMECHANICAL PROPERTIES OF POLYMERIC MATERIALS PRODUCED BY A 3D PRINTING METHOD
}

\author{
Adam GNATOWSKI, Rafał GOŁĘBSKI, Piotr SIKORA
}

\begin{abstract}
A comparative analysis of the thermomechanical properties of semicrystalline and amorphous polymeric materials was carried out. Samples were produced by using a 3D printing technology on the SIGNAL printer - ATMAT. The following polymeric materials were used to make the samples: TPU-thermoplastic polyurethane elastomer, ABScopolymer acrylonitrile-butadiene-styrene, Nosewood, PET-ethylene terephthalate, PLA-poly (lactic acid). The research included a thermal analysis of the dynamic properties (DMTA) of manufactured materials.
\end{abstract}

Keywords: polymer materials; thermal analysis of dynamic properties; 3D print

\section{INTRODUCTION}

3D printed parts are more and more often used in different industry branches as specially prototyping and commonly used items. Those sectors use the printing technology due to the short time between the project and final item production, and also because of the lower prices of manufacturing small batches compared to the injection moulding technology. Furthermore, 3D printing gives an opportunity to change the shape of the next part only by adding some changes in the $3 \mathrm{D}$ model. It also gives us the possibility of creating very complicated shapes $[1,2]$. Modern printers, due to the new software and hardware could spread subsequent filament layers more precisely, as they help them reach narrow dimensional and position tolerances of the printed elements. Among the tested materials used for 3D printing, you can find Laywood wood-like material, which after printing gives the elements the appearance of fibreboard and could be further processed by turning, milling grinding and could be painted as normal wood. This material is used to manufacture architectural models, decorations and furniture elements [3]. The amorphous acrylonitrile butadiene styrene used in the 3D printing technology is a high strength material since it works well when printing moving parts due to good temperature resistance and increased elasticity [4]. On the other hand, when this material is heated, it releases intense chemical vapours which are harmful for human being and animals, which is why such printing material should be placed in enclosed printers placed in a well-ventilated room. PLA is another test material, one of the most commonly used 3D printing materials characterized by biodegradability, since it is made of easily degradable materials. This material is characterized by a slight shrinkage of the material, which makes it ideal for demonstration prints such as mock-ups or prototype elements. PLA is not suitable for printing moving parts due to its low flexibility and low temperature resistance [5].

An important part of 3D printing is the appropriate choice of a material which will fulfil all our needs associated with our printed element. An incorrect selection of the material and process parameters associated with the type of element that will be manufactured and its functions may cause problems, such as, for example, early wear of the element, difficulties in obtaining adequate model accuracy, inaccurate filling of internal spaces, etc. Another difficulty in the process of $3 \mathrm{D}$ printing is the selection of adequate parameters for filament type processes, such as the printing temperature or the working table temperature. Incorrect selection of these factors may result in: clogging printer nozzles, larger material shrinkage than the expected, incomplete plasticization when applying subsequent layers, resulting in delamination of the element and the occurrence of non-uniformity of the model filling which causes a decrease in its strength [6-8].

The aim of the paper is to analyse changes in the thermomechanical properties as a function of the temperature and vibration frequency of materials used to manufacture products by using $3 \mathrm{D}$ printing. The polymers were chosen because they are widely used in 3D printing. Some of these materials are not suitable for injection moulding due to the clogging of injection channels or too long exposure to higher temperatures, which changes the properties of the injected material such as Laywood. Tests were conducted for comparison purposes for significantly different materials. The following materials were used as a test material: ABS, Laywood, PLA, PET, TPU. A thermal analysis of the dynamic properties (DMTA) was performed. Researches show that thermomechanical properties of these materials are strictly dependent on the processing method. To obtain those comparisons, the paper examines the samples made by the injection moulding and printing technology [9-15]. In order to compare the properties of the samples produced by $3 \mathrm{D}$ printing and injection, samples were made from the ABS material, which is widely used in many industry branches. This enabled the determining of the differences between the properties of the tested materials obtained in various processing technologies.

\section{RESEARCH METHODOLOGY}

The DEVIL DESIGN filaments with a thickness of 1.75 $\mathrm{mm}$ were used in the research.

They were made of the following polymer materials: Laywood, ABS, PLA, PET, TPU. Samples were made by 
using the 3D printing technology on an ATMAT SIGNAL printer, with the option of mounting nozzles with a throughgoing from $0.1 \mathrm{~mm}$ to $1.0 \mathrm{~mm}$. A printer nozzle can warm up to $270{ }^{\circ} \mathrm{C}$, while the table can reach a temperature of $110^{\circ} \mathrm{C}$. The accuracy of filament printing is $0.1 \mathrm{~mm}$ for the speed from 0.1 to $1 \mathrm{~cm}^{3} / \mathrm{min}$. 3D printing was done by using a 0.8 mm nozzle and the DIMAFIX adhesive for printing was applied to the table and printing parameters were used, and the most favorable properties were obtained. Parameters at which 3D printing samples were produced guaranteed the stability of the printing process, no deformation and favourable thermomechanical properties (Tab. 1). The filament feeding speed was used in accordance with the manufacturer's recommendations, and print cooling was also applied. The layer height of $0.21 \mathrm{~mm}$ was adopted.

\begin{tabular}{|c|c|c|c|c|}
\hline Sample & $\begin{array}{c}\text { Nozzle } \\
\text { temperature, } \\
{ }^{\circ} \mathrm{C}\end{array}$ & $\begin{array}{c}\text { Table } \\
\text { temperature, } \\
{ }^{\circ} \mathrm{C}\end{array}$ & $\begin{array}{c}\text { Printing } \\
\text { speed, } \mathrm{mm} / \mathrm{s}\end{array}$ & $\begin{array}{c}\text { Fulfilment, } \\
\%\end{array}$ \\
\hline LAYWOOD & 220 & 55 & 60 & 96 \\
\hline ABS & 230 & 100 & 60 & 96 \\
\hline $\begin{array}{l}\text { PLA } \\
\end{array}$ & 230 & 55 & 60 & 96 \\
\hline PET & 242 & 60 & 50 & 96 \\
\hline TPU & 250 & 60 & 25 & 96 \\
\hline
\end{tabular}

Samples for comparative purposes made of injected ABS were produced on a Krauss Maffei type KM with a $30 \mathrm{~mm}$ diameter screw, LD ratio of 23, constant pitch over the entire length and mold closing force of $650 \mathrm{kN}$. The optimal properties of the specimens were obtained for the following injection parameters recommended by the material manufacturer:

- Injection temperature $-230^{\circ} \mathrm{C}$,

- Mold temperature $-60^{\circ} \mathrm{C}$,

- Holding pressure - $50 \mathrm{MPa}$,

- Maximum permissible pressure in the plasticizing system $-100 \mathrm{MPa}$,

- Time of clamping $-10 \mathrm{~s}$,

- Cooling time $-16 \mathrm{~s}$.

An analysis of the dynamic thermal properties was carried out with the NETZSCH DMTA 242 device with a handle for a three-point free bending sample in the form of a beam with the dimensions of $50 \times 10 \times 4 \mathrm{~mm}$. The samples in the holder were subjected to a sinusoidal force of $1 \mathrm{~Hz}$ and $10 \mathrm{~Hz}$ with constant amplitude, while heating the samples at a rate of $3{ }^{\circ} \mathrm{C} / \mathrm{min}$ from $20^{\circ} \mathrm{C}$ to a different temperature for the materials tested (Tab. 2).

Table 2 Temperatures of the DMTA testing

\begin{tabular}{|c|c|}
\hline Sample & DMTA \\
\hline LAYWOOD & $-50{ }^{\circ} \mathrm{C}-60^{\circ} \mathrm{C}$ \\
\hline PLA & $-50{ }^{\circ} \mathrm{C}-60^{\circ} \mathrm{C}$ \\
\hline TPU & $-50^{\circ} \mathrm{C}-170{ }^{\circ} \mathrm{C}$ \\
\hline ABS & $-50{ }^{\circ} \mathrm{C}-190{ }^{\circ} \mathrm{C}$ \\
\hline PET & $-50^{\circ} \mathrm{C}-200^{\circ} \mathrm{C}$ \\
\hline
\end{tabular}

The elastic modulus $E^{\prime}$ and the mechanical loss factor $\tan \delta$ were calculated on the basis of force and strain values in relation to the dimensions of the samples. In order to be sure of the results, all tests were repeated for three samples.

\section{DISCUSSION OF RESEARCH}

The results of the analysis of dynamic mechanical properties are presented in Figs. $1-5 a, 5 b$ in the form of graphs of changes in the modulus of the elasticity and tangent of the angle of the mechanical losses depending on the temperature and the frequencies of 1 and $10 \mathrm{~Hz}$. In the case of LAYWOOD, it was observed that the polymer is in the elastic deformation phase of about $54^{\circ} \mathrm{C}$. You can then see a quick transition to the glass transition phase state. At the beginning of the elastic deformation phase, the $\mathrm{E}^{\prime}$ module is strongly dependent on the temperature of $-30{ }^{\circ} \mathrm{C}$ and the relationship decreases significantly. In this phase, the $E^{\prime}$ module drops from $2700 \mathrm{MPa}$ to $1800 \mathrm{MPa}$ at 54 degrees Celsius. In this phase, it can be concluded that the tangent of the mechanical loss angle is characterized by a small dependence on the temperature, ranging from $-10{ }^{\circ} \mathrm{C}$ to 54 ${ }^{\circ} \mathrm{C}$. The transition to the elastoplastic state occurs rapidly at $54{ }^{\circ} \mathrm{C}$, when the $E^{\prime}$ module rapidly decreases with a simultaneous sudden increase in $\tan \delta$ several times. This means that the polymer begins to bend and does not back to its normal shape, i.e. it bends permanently. That is why the machine could not read the data and that is why the chart ends at about $62{ }^{\circ} \mathrm{C}$.

Fig. 2 is similar to Figure 1 because the LAYWOOD material is made of PLA with the addition of wood chips, which is why DMTA for PLA ends in the same way as LAYWOOD.

In the elastic deformation phase of PLA DMTA, which ends at $-57{ }^{\circ} \mathrm{C}$, the $E^{\prime}$ modulus shows a negligible temperature dependence and is shaped at $4800 \mathrm{MPa}$, while the $\tan \delta$ values increase almost twice, showing a strong temperature dependence. The glass transition phase starts at $51^{\circ} \mathrm{C}$ and the chart ends at about $62{ }^{\circ} \mathrm{C}$ for reasons similar as to why LAYWOD is characterized by an extension between $-42^{\circ} \mathrm{C}$ and $56^{\circ} \mathrm{C}$. In this phase, the tan $\delta$ increases slightly to 0.08 , and finally the phase is reduced to 0.05 , followed by an increase in the tangent of the mechanical loss angle, which indicates the variability of vibration damping and material rigidity in the glass transition phase and a strong temperature dependence of the mechanical loss angle $[9-12,16]$.

In the case of TPU (Fig. 3), the elastic deformation phase ends at $-47^{\circ} \mathrm{C}$. The glass transition phase occurs in a wide temperature range, form $-47^{\circ} \mathrm{C}$ to $30^{\circ} \mathrm{C}$, in which $\mathrm{E}$ 'and tan $\delta$ show a strong temperature dependence. A high-viscoelastic deformation phase is extended in a wide temperature range: between $30{ }^{\circ} \mathrm{C}$ and $95{ }^{\circ} \mathrm{C}$, and here you can see a strong temperature dependence of $\tan \delta$, which indicates the variability of vibration damping and material rigidity. The high-viscoelastic deformation phase begins with a rapid reduction in the value of $\tan \delta$ (from 0.17 to 0.04 ), which is associated with strong elasticity at ambient temperatures and a poor dependence of the $E^{\prime}$ module on the temperature. In the elastic transition phase, it starts at $95{ }^{\circ} \mathrm{C}$, where the polymer begins to flow. 


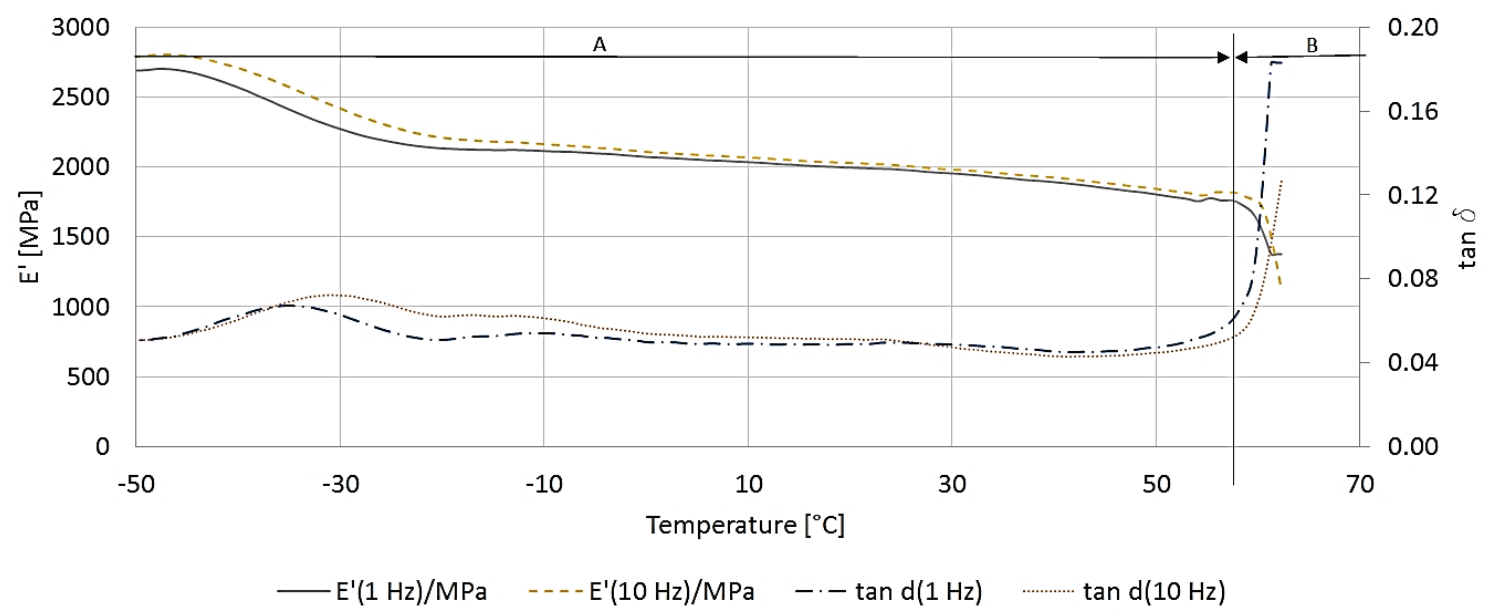

Figure 1 Results of DMTA investigations of LAYWOOD: A - elastic deformation phase; $B$ - glass transition phase; $C$ - high-viscoelastic deformation phase.

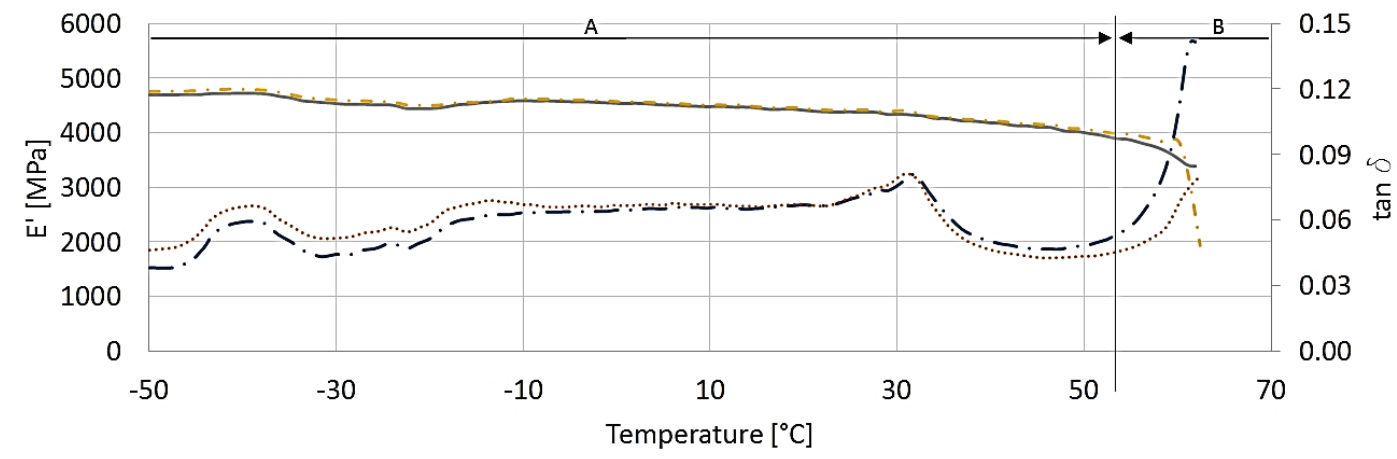

$-E^{\prime}(1 \mathrm{~Hz}) \quad-\cdot-\mathrm{E}^{\prime}(10 \mathrm{~Hz}) \quad-\cdot-\tan \mathrm{d}(1 \mathrm{~Hz}) \quad \cdots \cdots \cdot \tan \mathrm{d}(10 \mathrm{~Hz})$

Figure 2 Results of DMTA investigations of PLA: A - elastic deformation phase; $B$ - glass transition phase; $\mathrm{C}$ - high-viscoelastic deformation phase.

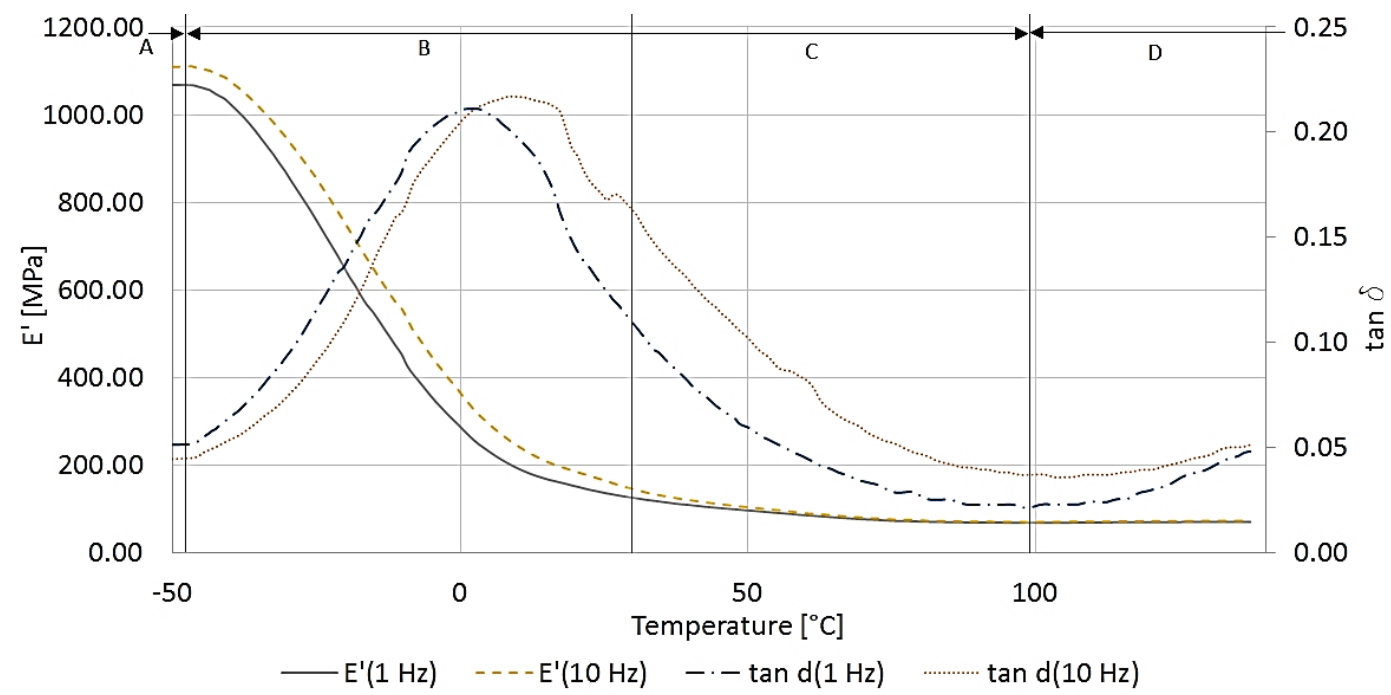

Figure 3 Results of DMTA investigations of TPU: A - elastic deformation phase; B - glass transition phase; C - high-viscoelastic deformation phase; D - elastic transition phase.

Fig. 4 shows the dependence of $\tan \delta$ and $E^{\prime}$ on temperature and frequency for PET. This material is a brittle and rigid body in the elastic deformation phase up to $73{ }^{\circ} \mathrm{C}$, in which $\tan \delta$ and $E^{\prime}$ are poorly dependent on temperature. In the glass transition phase, the dependence of $E^{\prime}$ is substantial, because the $E^{\prime}$ modulus is reduced from $2400 \mathrm{MPa}$ to 200 $\mathrm{MPa}, \tan \delta$ shows a notable temperature dependence rising from 0.05 to 0.5 and at the end of the phase, it drops to 0.18 at the smallest frequency of extortion. The high-viscoelastic deformation phase begins with a rapid decrease of $\tan \delta(1 \mathrm{~Hz})$ from 0.18 to 0.02 at $122{ }^{\circ} \mathrm{C}$ and at this temperature, the highviscoelastic deformation phase begins [16-18]. Maximum $\tan \delta$ indicates that PET samples made in $3 \mathrm{D}$ printing do not show a high vibration damping ability and are characterized by low stiffness in relation to the other tested materials. 




$\mathrm{E}^{\prime}(1 \mathrm{~Hz}) / \mathrm{MPa} \quad--\cdot \mathrm{E}^{\prime}(10 \mathrm{~Hz}) / \mathrm{MPa} \quad-\cdot-\tan \mathrm{d}(1 \mathrm{~Hz}) \quad \cdots \cdots \cdots \cdot \tan \mathrm{d}(10 \mathrm{~Hz})$

Figure 4 Results of DMTA investigations of PET: A - elastic deformation phase; $B$ - glass transition phase; $C$ - high-viscoelastic deformation phase; $D$ - elastic transition phase.

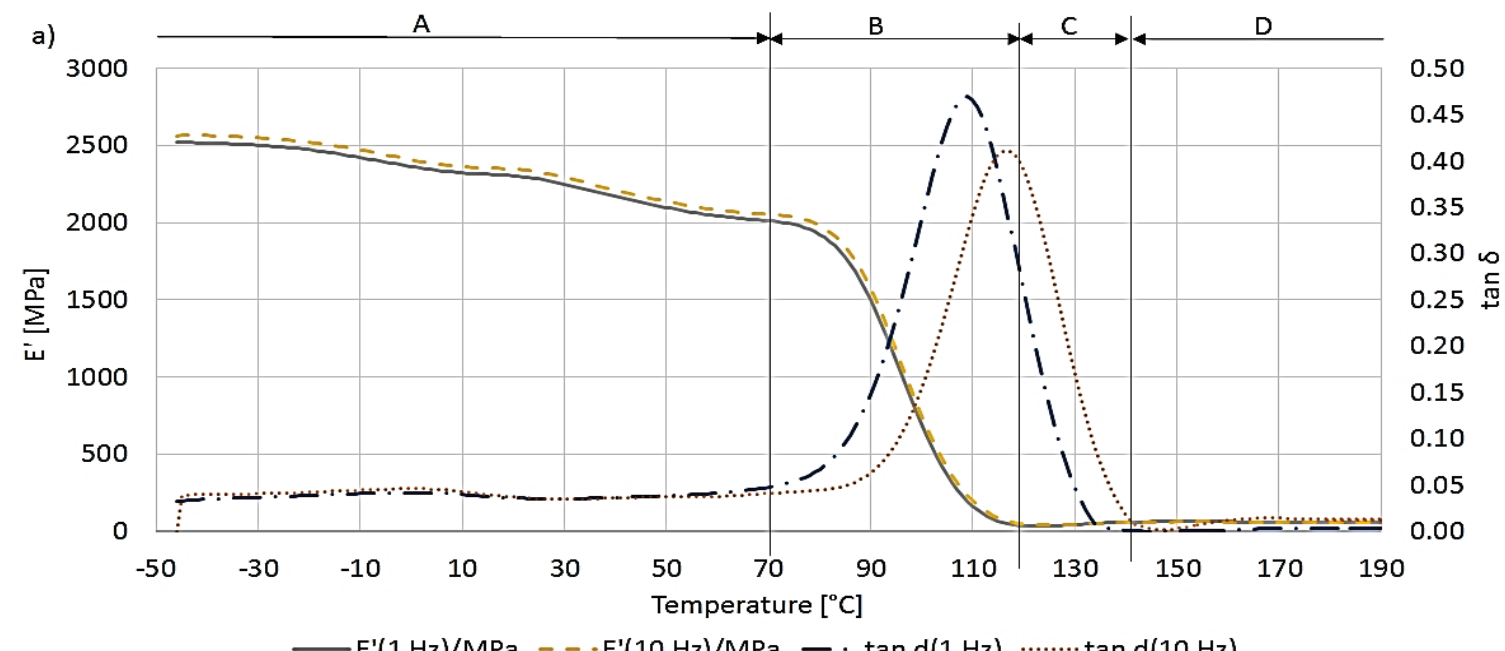

b)

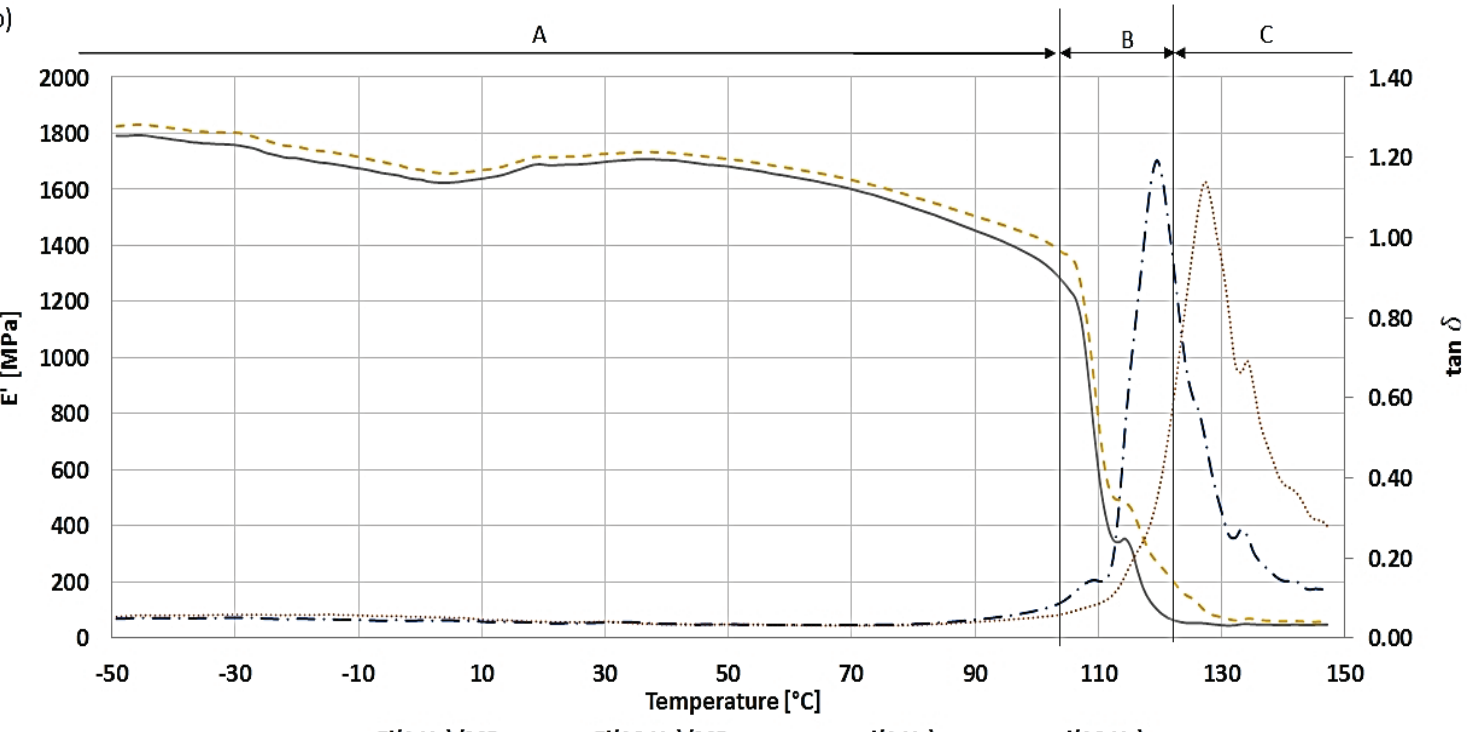

Figure 5 Results of DMTA investigations of: a) ABS from 3D printing, b) ABS from injecting: $\mathrm{A}$ - elastic deformation phase; $\mathrm{B}$ - glass transition phase; $\mathrm{C}-$ high-viscoelastic deformation phase. 
The graph of Fig. 5a shows the course of changes of the module $E^{\prime}$ and $\tan \delta$ as a function of temperature and frequency of vibrations for $\mathrm{ABS}$. In the case of $\mathrm{ABS}$, the elastic deformation phase ends at $93{ }^{\circ} \mathrm{C}$, smoothly going into the glass transition phase with a low temperature variation of $E^{\prime}$ and with a lack of $\tan \delta$ temperature dependence. The glass transition phase is characterized by almost tremendous temperature compliance at $93{ }^{\circ} \mathrm{C}$, and the module $E^{\prime}$ drops from $1450 \mathrm{MPa}$ to $100 \mathrm{MPa}, \tan \delta$ also shows temperature dependence because it goes from 0.1 to 1.2 and at the end of the phase drops to 0.6. In the high-viscoelastic deformation phase, $\tan \delta$ modules exhibit high temperature dependence, the $\tan \delta(1 \mathrm{~Hz})$ drops to 0.1 at $146{ }^{\circ} \mathrm{C}$. This polymer exhibits high stiffness and a very high vibration damping ability compared to the other tested samples as evidenced by the maximum $\tan \delta$ relaxation conversion for the smallest frequency of extortion.

The graph of Fig. $5 \mathrm{~b}$ shows the course of changes of the module $E^{\prime}$ and $\tan \delta$ as a function of temperature and frequency of vibrations for the ABS samples obtained by injection molding. These samples have the A phase, which starts from $2500 \mathrm{MPa}$, and it is more than the ABS printed samples have; in phase $\mathrm{B}$, the module $E^{\prime}$ drops very fast from $2000 \mathrm{MPa}$ to $150 \mathrm{MPa}$, and this drop is faster that in the printing samples, but $\tan \delta$ in this phase is rising only to 0.45 , i.e. it is 0.75 lower than in the $3 \mathrm{D}$ printed ABS. The phase $\mathrm{C}$ of the injected ABS is characterized by a fast drop of the $\tan \delta$ comparing to the printed $\mathrm{ABS}$, because $\tan \delta$ reaches the lowest level at $134{ }^{\circ} \mathrm{C}$, while printed $\mathrm{ABS}$ reaches the lower level of $\tan \delta$ at more than $150^{\circ} \mathrm{C}[6,11-14,19]$

\section{CONCLUSIONS}

An analysis of the results indicated that the samples made of Semi-Crystalline Polymers are characterized by an extended glass transition phase, in which the $E^{\prime}$ and tan modules have strong temperature dependence. LAYWOOD and PLA are characterized by an extended glass transition phase, after which the material begins to flow. On the other hand, the TPU polymer is characterized by a glass transition phase in which both the $\tan \delta$ and $E^{\prime}$ modulus show a high temperature dependence at the lowest temperature in the samples tested. In PET, as well as the ABS, in both highviscoelastic deformation phases, there is no temperature dependence of $E^{\prime}$ and $\tan \delta$ is decreasing to the lowest level showing high temperature dependence. Analyzing the changes in the tangent value of the mechanical loss angle, it was found that the highest stiffness and damping ability is found in ABS in comparison to the remaining samples tested. The smallest stiffness and low vibration damping capacity is characterized by PLA. Moreover, ABS obtained from injection seams to act more stable when we heat it, but ABS samples obtained from 3D printing have a better vibration dumping ability than the injected samples. 3D printing also has some disadvantages such as: long production time comparing to the injection time, printed elements have pores that allow air and water to get through, it is impossible to get sharp angles because printers are limited by nozzle dimensions, when angle is lower than 20 degrees, the printer will cut an area at end of angles due to minimal wall thickness, etc. Moreover, some of the printing filaments release intense chemical vapours that are harmful.

\section{REFERENCES}

[1] Siemiński, P. \& Budzik, G. (2015). Incremental techniques. 3D printing. $3 D$ printers, Warsaw, WNT.

[2] Štefanić, I., Raos, P., Samardžić, I., Tintor, B., \& Musser, E. (2012). Rapid prototyping of casting cores. Tehnički vjesnik, 19(2), 459-464.

[3] Kaziunas France, A. (2013). Make: 3D Printing: The Essential Guide to 3D Printers, Sebastopol, Maker Media.

[4] Barnatt, Ch. (2014). 3D Printing, Createspace.

[5] Wootthikanokkhan, J., Cheachun, T., \& Sombatsompop, N. (2013). Crystallization and thermomechanical properties of PLA composites: Effects of additive types and heat treatment. Journal Applied Polymer Science, 129, 215-223. https://doi.org/10.1002/app.38715

[6] Vaezi, M. \& Chua, C. K. (2011). Effects of layer thickness and binder saturation level parameters on $3 \mathrm{D}$ printing process. Advanced Manufacturing Technology, 53, 275-284. https://doi.org/10.1007/s00170-010-2821-1

[7] Zemcik, O. \& Sedlak, J. (2019). Application of Linear Optimization on Parameters of 3D FDM Print. Tehnički vjesnik, 26(4), 1164-1170. https://doi.org/10.17559/TV-20170506140109

[8] Gajdoš, I. \& Slota, J. (2013). Influence of printing conditions on structure in FDM prototypes. Tehnički vjesnik, 20(2), 231236.

[9] Stephens, P. A., Azimi, P., El Orch, Z., \& Ramos, T. (2013). Ultrafine Particle Emissions from Desktop 3D Printers, Atmospheric Environment, 79, 334-339. https://doi.org/10.1016/j.atmosenv.2013.06.050

[10] Gong, Y. \& Guisheng, Y. (2009). Manufacturing and physical properties of all-polyamide composites. Journal of Materials Science, 44(17), 4639-4644. https://doi.org/10.1007/s10853-009-3708-0

[11] Galeta, T., Šimunović, \& G., Mazurek, M. (2015). Impact of strengthening fluids on roughness of 3D printed models. Metallurgy, 24(1), 231-234.

[12] Sikora, P., Gnatowski, A., \& Gołębski, R. (2019) Tests of Mechanical Properties of Semicrystalline and Amorphous Polymeric Materials Produced by 3D Printing. MATEC Web of Conferences, 254. https://doi.org/10.1051/matecconf/201925406003

[13] Gnatowski, A. \& Chyra, M. (2016). Examinations of Thermomechanical Properties and Structure of Polyethylene with Cardboard Fibre and Colourant Composites after Electrochemical Ageing. Materials Engineering, 3, 120-125. https://doi.org/10.15199/28.2016.3.5

[14] Pavlic, T. \& Golubic, S. (2016), Analysis of the influence of 3D printing on hardness of parts. Tehnički vjesnik, 23(3), 843847. https://doi.org/10.17559/TV-20140901165134

[15] Tran, J. T. (2015). The Law and 3D Printing. John Marshall Journal of Computer \& Information Law, 31(4), 505-520.

[16] Gnatowski, A. (2010). Thermal Analysis of Dynamic Mechanical Properties and Research of the Structure and Crystallinities of Ultraviolet Radiation Ageing Polypropylene with the Dye Addiction. Composites Theory and Practice, 4, 328-332.

[17] Thomas, A. (2008). The 3D Trainwreck: How 3D Printing Will Shake Up Manufacturing. Analog, 128(11), 50-63.

[18] Juric, A., Stefic, T., \& Arbanas, Z. (2011). Eperimental analysis of the strength of a polymer produced from recycled material. Tehnički vjesnik, 18(4), 627-631. 
[19] Kumar, R.., Singh, R., \& Farina, I. (2018). On the 3D printing of recycled ABS, PLA and HIPS thermoplastics for structural applications. PSU Research Review. 2(2), 115-137 https://doi.org/10.1108/PRR-07-2018-0018

Authors' contacts:

Adam GNATOWSKI, Dr. Eng., Assoc. Prof.

Czestochowa University of Technology

Department of Technology and Automation

Al. Armii Krajowej 21, 42-201 Czestochowa, Poland

E-mail: gnatowski@ipp.pcz.pl

Rafał GOŁĘBSKI, Dr. Eng.

Czestochowa University of Technology,

Department of Technology and Automation,

Al. Armii Krajowej 21, 42-201 Czestochowa, Poland

E-mail: rafal@itm.pcz.pl

\section{Piotr SIKORA, MSC}

Czestochowa University of Technology,

Department of Technology and Automation,

Al. Armii Krajowej 21, 42-201 Czestochowa, Poland

E-mail: piotrek997@gmail.com 